\title{
GONÇALO M. TAVARES NO REINO DOS CAPITAIS CIRCULANTES
}

\author{
Júlia Vasconcelos Studart \\ UNIRIO
}

RESUMO: 0 texto é uma breve arqueologia do homem com a máquina a partir da série 0 Reino, de Gonçalo M. Tavares e do quanto e como este projeto, composto por quatro romances, se organiza em torno de uma morfologia esférica que vem da modernidade até o presente - 0 espaço contemporâneo - cumprindo à risca uma espécie de denúncia da coreografia desoladora do homem e sua posição no mundo em meio às máquinas fortes repetidoras da catástrofe.

PALAVRAS-CHAVE: Esfera. Máquina. Transparência.

\section{GONÇALO M. TAVARES IN THE KINGDOM OF CIRCULATING CAPITALS}

ABSTRACT: The text is a brief archeology of the man with the machine based on the 0 Reino series, by Gonçalo M. Tavares, and how this project, which is composed by four novels, is organized around a spherical morphology that follows modernity until the present time - the contemporary space -, fulfilling to the letter a kind of complaint of the desolating choreography of the man and its stance in the world amidst strong machines repeaters of the catastrophe.

KEYWORDS: Sphere. Machine. Transparency.

Júlia Vasconcelos Studart é professora da Escola de Letras da Universidade Federal do Estado do Rio de Janeiro. 


\title{
GONÇALO M. TAVARES NO REINO DOS CAPITAIS CIRCULANTES
}

\author{
Júlia Vasconcelos Studart
}

É Sloterdijk que lança a pergunta a partir da leitura que faz de Heidegger: onde estamos quando dizemos que estamos no mundo. Esta proposição interrogativa diz sobre os diferentes formatos de estar no mundo e como isto é um problema do espaço. Ele afirma que é preciso "interpretar o lugar do homem como esfera, visto que não me sinto à vontade com essa fria e ilhada fórmula sonora de estar-no-mundo." ${ }^{1}$ A leitura que faz do conceito de mundo de Heidegger como excessivamente metafísico toca o que ele chama de conceito saturado de totalidade. Imagina que usar mundo e não esfera coloca um impasse para a proposição, seria algo como ter que contar a história de cada homem individualmente. A questão é, para ele, como gerar um pensamento morfológico, por que insiste que o problema fundamental do homem é o espaço e é com o espaço, ou seja, que a vida é um assunto de forma por que existem vários formatos de estar no mundo. Por isso que a passagem articulada por uma teoria esferológica lhe é tão cara como instrumento morfológico de investigação, por que aponta para uma história que vai de uma posição metafísico-cosmológica até a constituição de condições para os artifícios de imunidade humana. Esse pensamento da esfera segue o que ele chama de "globalização morfológica, ou melhor, onto-morfológica em honra da predilecção da teoria clássica do ser pelas figuras esféricas" ${ }^{2}$ e se propaga no conjunto de relatos que matizam a vida numa espécie de proteção artificial, e é a isto que ele chama imprecisamente de pós-história:

Pertence às ironias da Modernidade aquilo que precisou ser proibido retroativamente, isto é, tudo o que se empreendeu e o que se colocou em risco para torná-la realidade. Assim, disso decorre que a chamada pós-história apenas apa-

\footnotetext{
${ }^{1}$ SLOTERDIJK, Peter; HEINRICHS, Hans-Jürgen. El sol y la muerte. Trad. Germán Cano. Madrid: Siruela, 2004, p. 175.

2 SLOTERDIJK, Peter. Palácio de Cristal. Para uma teoria filosófica da globalização. Trad. Manuel Resende. Lisboa: Relógio D’Água, 2008, p. 19.
} 
rentemente representa um conceito histórico-filosófico, ou seja, uma referência à técnica de seguros; pós-históricas são todas as situações em que estão proibidas por lei ações históricas (fundação de religiões, cruzadas, revoluções, guerras de liberação, luta de classes com todos seus traços heroicos e fundamentalistas) por causa de seu risco não assegurável. ${ }^{3}$

A partir daí, tem-se que o percurso que faz desse pensamento esferológico em direção à poshistoria vai da primeira esfera, as bolhas, como estruturas relacionais e bipolares que produzem uma intimidade mínima e possível tal qual um espaço oco; depois o globo, que figura a imagem daquilo que põe em compasso as mais diversas formas de globalização que, por sua vez, fundam um mundo sincro entre a circulação do dinheiro e das imagens em tempo real, ou seja, que habitar o mundo agora é habitar de fato uma guerrilha globalizada - quando "a humanidade se encontra hoje diante de um processo monstruoso de entrelaçamento e de mobilização repleto de riscos possíveis, impulsionado por ideias não menos ilusórias acerca da compatibilidade e da confusão de tudo com tudo" ${ }^{4}$ e quando "no reino dos capitais circulantes o momentum foi substituído pelos fundamentos. Consumação substitui a legitimação; os fatos foram convertidos em normas e níveis." 5 Sloterdijk afirma que para o homem moderno a imagem do mundo se dá num corte entre o novo e o velho, o que gera um apontamento para o homem contemporâneo acerca de sua condição humana, sua condição de vida, numa crise da imagem do mundo com suas extensões desmesuradas:

A era moderna é o período em que se difunde uma nova evidência incomensurável, em relação a todo o período anterior, sobre a situação cósmica do homem. [...] A ideia de que 'esta Terra vale mais do que todo o céu restante'. Essa verificação, em parte, precisa ser compreendida de maneira totalmente literal. Um dos traços distintivos da era moderna, que até então foi apenas advertido, está no fato de que nesta época a situação do homem, dentro do cosmos, se apresenta ao abrigo de duas esferas. A do céu e a do globo terrestre, dois meios de massas da metafísica colocada em movimento, em que se articulam a visão temporal moderna da conditio humana. ${ }^{6}$

A partir disso é possível tentar entender a globalização como uma conse-

\footnotetext{
${ }^{3}$ Idem, Esferas II. Globos. Macrosferologías. Trad. Isidoro Reguera. Madrid: Siruela, 2004, p. 778.

${ }^{4}$ SLOTERDIJK, Peter; HEINRICHS, Hans-Jürgen. El sol y la muerte, op. cit., p. 188.

${ }^{5}$ SLOTERDIJK, Peter. Esferas II, op. cit., p. 849.

${ }^{6}$ SLOTERDIJK, Peter; HEINRICHS, Hans-Jürgen. El sol y la muerte, op. cit., p. 190.
} 
quência de um processo de destruição das distâncias, por que estamos presos, diz ele, nesse processo. O que acontece é que o espaço discreto, emancipador, separador e que realmente se expande territorialmente está sendo destruído pela velocidade e imposição absoluta do tempo. A globalização, pois, é "a consequência do movimento do capital especulativo que circunda a terra sob a forma de notícias dadas na velocidade da luz. Portanto, esse tipo de globalização equivale a uma espécie de destruição do espaço." ${ }^{7}$

Para repensar esta conditio humana a partir da visão temporal da modernidade, estabelece, por fim, a figuração das espumas, que são uma espécie de terceira globalização, uma superfície homogênea que se dá depois do imperialismo marítimo e aéreo da velocidade - "o face a face de todas as superfícies do globo" ${ }^{8}$, diz Paul Virilio de outra maneira. Essa globalização, desdobrada numa metaforização como espumas, apresenta, sobretudo, "a virtualização do espaço, atuada por meio do dinheiro rápido e da informação rápida. Quando as sociedades impulsionam uma produção excessiva de imagens e de textos surge a espuma." ${ }^{9}$ Para Sloterdijk, os homens que produzem as espumas "discursos sem controles de referentes externos, produção caótica de sentido, vertigem crônica" ${ }^{10}$ - não são capazes nem de formar duplas ideais nem de salvar a si mesmos nos hiperglobos do cosmo único e imunizador ou de um Deus único. Por que o problema é a coexistência do ser humano com o outro que sai de uma relação parental para aquilo que provoca a emergência do político.

No seu projeto $O$ Bairro, por exemplo, Gonçalo M. Tavares procura contrariar essa imposição dos produtores de espumas, por isso escolhe como moradores dessa conurbação imaginada não apenas o homem assolado pelas formas de vida modernas/contemporâneas e adequado a elas, mas opta por uma constelação de artistas que, em algum momento de suas vidas e, principalmente, com os seus trabalhos, enfrentaram os aspectos estetizantes da vida moderna: da política à própria circulação da arte como autonomia e reinvenção permanente, da utilização da ciência às máquinas de facilitação da vida, do que pode gerir e engendrar potência e vontade, felicidade e graça. Um tipo de aprendizagem ou de reaprendizagem do sentimento do espaço, como

\footnotetext{
${ }^{7}$ Ibidem, p. 196-197.

${ }^{8}$ VIRILIO, Paul. Velocidade e política. Trad. Celso M. Paciornik. São Paulo: Estação Liberdade, 1996, p. 125.

${ }^{9}$ SLOTERDIJK, Peter; HEINRICHS, Hans-Jürgen. El sol y la muerte, op. cit., p. 182.

${ }^{10}$ Ibidem, p. 182.
} 
diz Nietzsche num fragmento de Aurora:

Foram as coisas reais ou as coisas imaginadas que mais contribuíram para a felicidade humana? É certo que a amplidão do espaço entre a suprema felicidade e a mais profunda infelicidade foi criada apenas com o auxílio das coisas imaginadas. Esse tipo de sentimento do espaço, então, é reduzido cada vez mais pela ação da ciência: de modo que dela aprendemos a perceber a Terra como pequena, e o próprio sistema solar como um simples ponto. ${ }^{11}$

Por outro lado, no projeto O Reino - os livros intitulados Um homem: Klaus Klump (2003), A Máquina de Joseph Walser (2004), Jerusalém (2004) e Aprender a rezar na era da técnica (2007), publicados nessa ordem, de certo modo, formam um só livro e os acontecimentos avançam num mesmo cenário. Gonçalo M. Tavares opta por sujeitos com nomes que não tenham indicação biográfica, muito menos localização, e usa nomes de um étimo germânico confuso (como, por exemplo, seguindo a ordem de publicação, os protagonistas Klaus Klump, Joseph Walser, Theodor Busbeck e Lenz Buchmann). Estes sujeitos podem aparentemente se embrenhar em si mesmos, nos seus hábitos mais íntimos, sem conseguir liberar qualquer motivação pânica para compor qualquer trabalho de risco ou desviante das suas formas mais corriqueiras.

Esses personagens lidam com aspectos de integração e assimilação com o espaço, fundem-se ao espaço quando se desmobilizam dele. O mundo passa a ser uma cola, uma areia movediça, um terreno pantanoso que ao sugar o homem transforma esta simbiose - homem/mundo - na única alternativa de lugar seguro e imunizador. Hinnerk, um personagem lateral de Jerusalém, é um bom exemplo dessa imposição simbiótica que se apresenta em todos os personagens de $O$ Reino: "Com os hábitos certos e monótonos Hinnerk procurara diminuir as possibilidades daquilo a que se poderá chamar o novo. Rapidamente, em tempo de paz, percebera a ligação entre o medo e o imprevisto, e assim tentara colocar em cada um dos seus dias um rigor de patrulha." ${ }^{12} \mathrm{Ou}$ numa pequena descrição em A máquina de Joseph Walser: "É domingo e os casais mais determinados beijam-se. As relações habituais não gostam de desvios." 13

\footnotetext{
${ }^{11}$ NIETZSCHE, Friedrich. Aurora. Trad. Paulo César de Souza. São Paulo: Companhia das Letras, 2008, p. 16-17.

12 TAVARES, Gonçalo M. Jerusalém. São Paulo: Companhia das Letras, 2006, p. 62.

${ }^{13}$ Idem, A máquina de Joseph Walser. Lisboa: Caminho, 2006, p. 41.
} 
Sloterdijk afirma que a modernidade estética é um procedimento de uso da violência, não contra pessoas ou coisas, mas sim contra circunstâncias culturais pouco claras. Diz ele que "dado que nesta guerra de mentalidades a normalidade é considerada um crime, então, a arte, como meio de luta contra o crime, pode apoiar-se em ordens de entrada em ações não usuais." ${ }^{14}$ Tanto que lembra a passagem do Segundo Manifesto Surrealista, de 1930, escrito por André Breton, que afirmou que a ação surrealista mais simples consiste em ir para rua com revólveres em punho e disparar às cegas na multidão tantas vezes quanto for possível. Breton é um dos senhores escolhidos por Gonçalo M. Tavares para morar no bairro, o que tem a ver com um posicionamento do homem no mundo a partir daquilo que a arte é capaz de gerar como risco, logo, como política, como não-familiar, como projeção futura e utópica. É uma pequena reação contemporânea para não correr o risco de se associar ao hábito da modernidade de converter tudo em regra, mesmo a imitação do ato bárbaro. Por outro lado, os personagens de O Reino - quase em forma de uma denúncia do modus vivendi nesta passagem do moderno para o contemporâneo - não demoram em incorporar o que antes parecia estranho ou diferente como um próprio ou como uma segunda natureza. Basta ver o que pensa Klaus Klump em relação à guerra que o interrompe e o lança no mundo sem história ou numa história perdida diante de um novo Deus, o som da bala e da bomba:

Nem o som das frases dos livros, nem o som das coisas naturais a baterem em outras coisas naturais, nem estes dois sons misturados no acto da física amorosa: a cabeça de Klaus estava agora fascinada pelo som, quase estúpido, quase sem História, da bala e da bomba. O som que anunciava um novo Deus. ${ }^{15}$

E também a fala de um sobrevivente que Theodor Busbeck, o médico protagonista de Jerusalém, anota em seu caderno preto: "O sobrevivente de um campo de concentração disse: 'Os homens normais não sabem que tudo é possível'. Theodor sublinhou a frase." ${ }^{16}$

Por isso que a representação da espuma, assim como todo o discurso em torno das esferas, ao dizer tanto da co-fragilidade quanto do isolamento do

\footnotetext{
${ }^{14}$ SLOTERDIJK, Peter. Esferas III. Espumas. Esferología plural. Trad. Isidoro Reguera. Madrid: Siruela, 2009, p. 130.

${ }^{15}$ TAVARES, Gonçalo M. Um homem: Klaus Klump. São Paulo: Companhia das Letras, 2007, p. 88.

${ }^{16}$ TAVARES, Gonçalo M. Jerusalém, op. cit., p. 62.
} 
homem, diz das unidades comunicantes da vida moderna que tocam o espaço contemporâneo como um processo de força para a relação fundamental do ser-no-mundo, as formas de habitar o mundo que se organizam a partir de seus espaços fechados como estruturas globalizadas de condicionamento da vida, de proteção e de imunização. Essa teoria da espuma, para Sloterdijk, segue um percurso regido pela esferologia até um volume próprio de suas unidades comunicantes:

\begin{abstract}
À teoria da espuma se vincula a possibilidade de uma nova forma de explicação daquilo que a tradição sociológica chama nexo social ou "síntese social"; a possibilidade de uma explicação que vá mais além das respostas clássicas à pergunta cristã de como é possível a 'sociedade' como conexão de seres sociais. As conhecidas propostas de solução, submetidas a critérios como divisão do trabalho (Smith, Durkheim), relação de Capital (Marx), imitação e sonambulismo (Tarde), interação (Simmel), sacrifício (Girard, Heinrich) ou diferenciação e comunicação (Luhnmann), adoecem do mesmo déficit, a saber, que não nos expressam adequadamente nem as qualidades espaciais das células sociais, nem o caráter imunológico dos espaços primários.

As multiplicidades espaciais, projetadas segundo as regras mediáticas e psicológicas do jogo do individualismo, extremamente próximas e semitransparentes uma em relação à outra, também se chamam espumas porque é necessário ressaltar sua improbabilidade sem que seja lícito considerar sua fragilidade como rendimento vital deficiente dos habitantes da espuma. ${ }^{17}$
\end{abstract}

De certa maneira, ler a arqueologia de composição do projeto O Reino é ler a oscilação da passagem esferológica da modernidade para a contemporaneidade proposta por Sloterdijk. Oscilação que recupera o procedimento da escrita de Gonçalo M. Tavares quando procura colidir a construção de sua literatura, entre o poema e a ficção, com a filosofia e a história. A ideia é gerar uma escrita que seja um motor de investigação e também a formulação de um pensamento. Essa arqueologia de composição aparece também na perspectiva e nos formatos de como trabalha o espaço, que agora é múltiplo e habitado por personagens desolados e desoladores como um processo no mundo e vir-ao-mundo: "O processo de vir-ao-mundo no homem é um contínuo que integra momentos descontínuos." ${ }^{18}$ Num primeiro momento, são homens plenamente frágeis, depois, porém, contraditoriamente muito fortes e tomados de doses sempre suspeitas de individualismo cruel. Procuram uma saída con-

\footnotetext{
${ }_{17}^{17}$ SLOTERDIJK, Peter. Esferas III, op. cit., p. 194.

${ }^{18}$ SLOTERDIJK, Peter; HEINRICHS, Hans-Jürgen. El sol y la muerte, op. cit., p. 198.
} 
vulsa para restar no mundo e organizar polos intensos de imunização. Sloterdijk insiste que a característica mais forte das formas de vida individualistas é ter que inventar conformações de espaço em meio às novas situações do mundo contemporâneo causadas por sua extrema mobilidade: "estabilidade por liquidez: esta fórmula pós-moderna penetra diretamente no núcleo da imunologia geral. Nunca antes a manutenção da autoafirmação dependeu de tantas prestações adicionais, que superam o nível defensivo." ${ }^{19}$

Um ponto de entendimento do projeto O Reino parte da impressão que o termo "reino" implica numa transparência em direção ao termo "bairro", por exemplo, como um procedimento para fazer colidir os espaços conformados. Podemos tentar entender esta ideia do "reino" como um espaço que não se vincula mais a uma cartografia territorial e como um trunfo sobre a distância e a terra, e muito mais como aquele espaço que não tem medida, um espaço de dimensões desmesuradas e que não para de crescer velozmente. Virilio se pergunta qual o problema agora, já que não é mais "de uma historicidade no tempo (cronológica) ou no espaço (geográfica), mas em qual espaço-tempo?" ${ }^{20}$ A vastidão desse espaço encobre aparentemente toda a esfera humana em suas formas individualistas de coexistência, principalmente as demarcações das formas de vida impostas pela cidade moderna e suas novas sugestões de experiência provocadas pela máquina e suas derivações micro-invisíveis, pela guerra, pelos coeficientes de velocidade, de distância, de geografia, de sobrevivência, de tecnologia, de horror e de contágio. Mais ou menos numa confusão entre tempo e espaço, como indica Celeste Olalquiaga, "na qual a continuidade temporal desaba na extensão e a dimensão espacial se perde para a duplicação, transforma a cultura urbana num gigantesco holograma capaz de produzir qualquer imagem dentro de um aparente vazio." ${ }^{21}$

Depois, é importante pontuar que a tetralogia elabora uma perspectiva ímpar e ao mesmo tempo parelha com os livros que formam O Bairro. Não só por que os livros das duas séries foram publicados concomitantemente, mas por que ao armarem uma espécie de transparência armam também um desdobramento numa direção que pode até parecer contrária, mas de fato não é. Note-se que os livros que formam $O$ Reino têm como indicativo a denomina-

\footnotetext{
${ }^{19}$ SLOTERDIJK, Peter. Esferas III, op. cit., p. 194.

${ }^{20}$ VIRILIO, Paul. Velocidade e política, op. cit., p. 111.

${ }^{21}$ OLALQUIAGA, Celeste. Megalópolis. Sensibilidades culturais contemporâneas. Trad. Isa Mara Lando. São Paulo: Studio Nobel, 1998, p. 45.
} 
ção Livros Pretos $^{22}$ e, de todo modo, ainda seguem o modelo tradicional e moderno da forma romance - a narrativa burguesa que trata do apareIhamento da experiência moderna e do conhecimento da experiência feérica quando lança a vida para baixo, para o mundo da prosa, do prosaico -, principalmente no que trata do uso exacerbado do fragmento, da frase curta e elíptica e das interferências de imagens umas nas outras, como também são livros movidos pela instalação convicta e, ao mesmo tempo, confusa da máquina de guerra, se pensamos com Nietzsche e também com Deleuze e Guattari - "O Estado não para de produzir e reproduzir círculos ideais, mas é preciso uma máquina de guerra para fazer um redondo" ${ }^{23}$-, e são propriamente livros de força $a^{24}$, se pensados com Nietzsche: "Eu conheço o prazer de destruir em um grau conforme a minha força para destruir - em ambos obedeço à minha natureza dionisíaca, que não sabe separar o dizer Sim do fazer Não. Eu

22 O livro intitulado água, cão, cavalo, cabeça é anotado por Gonçalo M. Tavares como fazendo parte do conjunto livros pretos, mas não da série $O$ Reino. Mas é interessante indicar que o livro, composto de 25 narrativas curtas, é praticamente um mapa das questões que vai tratar nessa série. Uma das narrativas, inclusive, se chama $O 4^{\circ}$ Reino. Nela, a questão gira em torno do terremoto como uma declaração de guerra da natureza contra uma família: um pai que tenta proteger o filho alvejado por uma bala. $O$ pai não consegue proteger de todo o corpo do menino, "o pai não é a mãe", pondera. A presença da guerra, de um engenheiro, de um médico, de crianças, de um aranhiço entre outras coisas indicam uma confusão generalizada entre os reinos que compõem o mundo: "Existe o reino vegetal, o reino mineral e o reino animal. Mas há depois outro, há depois outro." TAVARES, Gonçalo M. água, cão, cavalo, cabeça. Lisboa: Caminho, 2006, p. 40. Numa outra narrativa, chamada Os movimentos da ficção, há uma relação entre a palavra e o mundo, o quanto uma palavra não é ou não diz, que indica a convicção de sua tarefa com a literatura em torno da imaginação como política e construção utópica, e também do desenho do espaço que vai compor a série $O$ Reino entre a cidade e o corpo: "Com as palavras podes escrever palavrasficção. Na verdade também me é difícil conceber ideias não reais, ideias ficcionais. [...] É preciso ter medo dos homens e das mulheres cansadas. E a cidade é rápida de mais, empurra-nos para o nosso corpo pior (de entre vários possíveis)." Ibidem, p. 53-54.

${ }^{23}$ DELEUZE, Gilles; GUATTARI, Félix. Mil Platôs. Capitalismo e esquizofrenia, v. 5. Trad. Peter Pál Pelbart e Janice Caiafa. São Paulo: 34, 2005, p. 34.

${ }^{24}$ Numa passagem de A máquina de Joseph Walser, por exemplo, o narrador coloca Walser como um manipulador do mundo e da vida, com força e prazer para destruir, quando sugere que ele repete o gesto de um Cesar romano e que pode decidir entre a vida e a morte de outrem com um simples movimento de seu dedo polegar da mão direita: "Naquele momento Walser sentia que controlava o mundo, que o manipulava, que era capaz de o fazer dizer sim ou não apenas pela ligeira alteração de movimento de um dos seus dedos. Como se o sim ou o não do mundo físico dependesse, naquele momento, exclusivamente, da orientação do seu polegar." TAVARES, Gonçalo M. A máquina de Joseph Walser, op. cit., p. 32. O gesto é às avessas ao gesto de um Cesar por que de fato não pode decidir nem impor nada a outrem. E o livro é um livro de força, mas Walser muitas vezes segue a ambivalência da natureza do homem. Por isso, nesse momento, se aproxima muito mais da formulação de Nietzsche ao se colocar como um imoralista par excellence. 
sou o primeiro imoralista: e com isso sou o destruidor par excellence." ${ }^{25}$

Em princípio, como sugere Roland Barthes, "o tempo foi o primeiro a sofrer as tentativas de destruição ou de remanejamento dos romancistas" ${ }^{26}$, haja visto, lembra ele, as técnicas de flashback ou simultaneidade. Mas a questão do espaço, emenda, "ainda está mais ou menos intacta." ${ }^{27} \mathrm{~A}$ simultaneidade comparece no projeto $O$ Reino quando as histórias e as personagens atravessam e saltam de uma narrativa a outra, numa temporalidade sem começo ou fim e permeada por uma argumentação paradoxal, degradada, inautêntica e desconfiada. É a escrita de um corpo alterado, da forma oscilante até o que a forma impulsiona como tema, ou como morfologia, numa espécie de coreo-grafia desoladora em torno da investigação da vida contemporânea como disparidade sucessiva e simultânea: uma poética política do espaço.

$\mathrm{O}$ caso de Leo Vast é exemplar. Ele é um personagem que aparece em Um homem: Klaus Klump, no meio da guerra, dono da fábrica em que trabalha Joseph Walser, por sua vez, o protagonista do segundo livro da série, que tem uma simbiose com a máquina que opera nesta fábrica de Vast. E Joseph Walser, quando perde um dedo enquanto opera esta máquina, é atendido por Lenz Buchmann, o médico protagonista do último livro da série, Aprender a rezar na era da técnica. Em A máquina de Joseph Walser pode-se ler: "TinhamIhe amputado o dedo indicador." ${ }^{28} \mathrm{e}$ "[...] Walser sentia que alguém, ou algo, Ihe havia roubado não apenas uma parte do corpo, mas movimentos. E esta consciência mudava completamente o entendimento que Walser fazia do acidente." ${ }^{29}$ Mas é interessante o que se pode ler na perspectiva da transparência que há entre um livro e outro: o cenário e o fragmento narrativo se repetem numa reprodução quase integral, muda-se o ponto de vista, mas há a manutenção do impasse da mutilação do corpo humano provocada pela simbiose com a máquina:

\section{A máquina de Joseph Walser}

\footnotetext{
${ }^{25}$ NIETZSCHE, Friedrich. Ecce homo. Como alguém se torna o que é. Trad. Paulo César de Souza. São Paulo: Companhia das Letras, 2008, p. 103.

${ }^{26}$ BARTHES, Roland. Inéditos, v. 2. Crítica. Trad. Ivone Castilho Banedetti. São Paulo: Martins Fontes, 2004, p. 101.

27 Ibidem, p. 101.

28 TAVARES, Gonçalo M. A máquina de Joseph Walser, op. cit., p. 81.

${ }^{29}$ Ibidem, p. 100.
} 
- Doutor - disse Walser, continuando a manter a sua mão direita ao lado do corpo - peço desculpa, mas estava há muito tempo a chamar os enfermeiros. $O$ médico não the respondeu. $O$ médico não the respondeu. Olhou-o de modo firme.

- Qual seu nome?

- Joseph Walser.

- Joseph Walser - repetiu o médico. — Pois bem, comporte-se, senhor Walser.

Está num hospital! - e virou-lhe as costas.

Uma enfermeira aproximou-se:

- Os momentos não são para fraquezas, caro senhor. O que lhe aconteceu é uma brincadeira. Fazia um enorme favor a todos se se comportasse como homem. $^{30}$

\section{Aprender a rezar na era da técnica}

Mas o mundo não parava e o Dr. Lenz Buchmann foi interrompido nestas considerações mentais e no seu cigarro por um pequeno tumulto: um civil que tivera um acidente de trabalho (nenhuma relação portanto com a explosão) e a quem haviam amputado o dedo indicador da mão direita, estava a perturbar, com os seus chamamentos sucessivos, o silêncio que se instalara no hospital. Queria chamar atenção da enfermeira e insistia em levantar-se da cama. Estava já, esse pequeno homem, no corredor, quando Lenz se lhe dirigiu para o repreender.

- Qual é o seu nome?

- Joseph Walser.

- Pois bem, senhor Joseph Walser, por favor, comporte-se.

O homenzinho ficou claramente embaraçado, e o Dr. Lenz virou-lhe as costas.

Que importância tem um dedo? Um cobarde, pensou. ${ }^{31}$

Leo Vast, pois, é o que se ocupa das opiniões convulsas. O narrador atribui a ele, por exemplo, a opinião neutra acerca da passagem de um estado totalitário para a democracia, ${ }^{32}$ que é tida por ele como uma falência da representação política e uma fraqueza global. A própria ideia de sociedade entra em xeque; é o começo de uma evaporação das concepções tradicionais do sujeito

\footnotetext{
${ }^{30}$ Ibidem, p. 76.

${ }^{31}$ Idem, Aprender a rezar na era da técnica. Lisboa: Caminho, 2007, p. 46.

${ }^{32}$ Nietzsche escreveu em Além do bem e do mal que a democratização na Europa resultava na criação de um tipo mais preparado para a escravidão em seu sentido mais sutil: "o homem forte, caso singular e de exceção, terá de ser mais forte e mais rico do que possivelmente jamais foi - graças à ausência de preconceitos em sua educação, graças à enorme diversidade de sua exercitação, dissimulação e arte. Quero dizer que a democratização da Europa é, simultaneamente, uma instituição involuntária para o cultivo de tiranos - tomando a palavra em todo sentido, também no mais espiritual." NIETZSCHE, Friedrich. Além do bem e do mal. Prelúdio a uma filosofia do futuro. Trad. Paulo César de Souza. São Paulo: Companhia das Letras, 1992, p. 150.
} 
político e da autonomia social, de força e de tirania:

A democracia instala-se no país como uma borracha que se vai derretendo lentamente até preencher por completo a superfície de um compartimento. Mas a democracia é a instalação da cobardia mútua, e tal sistema não parte nunca de uma vontade forte, de uma intenção original; pelo contrário: é consequência de uma matéria que derreteu. [...] A democracia é um efeito da perda de Força de um conjunto de homens. É um ganho de fraqueza global.

Era Leo Vast que assim pensava naquele instante. A borracha derreteu-se, murmurava ele. Derreteram a matéria forte e agora temos os pés instalados em esponjas. Não sabemos o que vai acontecer. ${ }^{33}$

Não saber o que vai acontecer ou tanto faz o que pode acontecer é o pensamento daquele dia, não do dia anterior ou do dia seguinte. Instalar-se numa esponja é instalar-se numa sucção simbiótica entre o homem e o mundo; habituar-se. Nesse sentido, o caso de Joseph Walser com o seu dedo amputado pela máquina também é exemplar. Num prosseguimento do exemplo, a fábrica de Leo Vast tem como encarregado Klober, o chefe direto de Walser, que teima em reproduzir a maneira de pensar de Vast, seu patrão:

Porque só as repetições acalmavam, só as repetições permitiam a cada indivíduo voltar a encontrar-se humano no dia seguinte [...] resistir no meio do reino da desordem, no meio daquilo que Klober costumava designar como século da imprevisibilidade, século não apenas contrário mas inimigo da repetição. Este não é um século normal, costumava dizer Klober, mas os homens deste século continuam a ser como sempre foram. E era esta, a mistura: Homens que repetiam os actos essenciais das gerações anteriores e que eram invadidos - e esta é uma utilização exacta do termo pois descreve o fluxo e a velocidade dos movimentos - eram invadidos, então, ao mesmo tempo, por fenómenos absolutamente novos.

Nenhum profeta havia sequer acertado na cor dos sapatos do século, dizia Klober, em tom de troça. ${ }^{34}$

E assim, com esses desenvolvimentos narrativos de repetição dos gestos e das imagens, se percebe o quanto há de um personagem no outro, de um livro no outro e, principalmente, como a ideia de construção desses personagens está vinculada à manifesta convicção de que esses personagens são os habitantes dessa esfera frágil, desigual, isolada, múltipla e permeada por uma liquidez ao mesmo tempo imprevista e demarcada. A esfera - que é este O Reino

33 TAVARES, Gonçalo M. Aprender a rezar na era da técnica, op. cit., p. 103.

${ }^{34}$ Idem, A máquina de Joseph Walser, op. cit., p. 118. 
- é permeável. São os novos fenômenos do século que sobressaltam e assombram, mas ao mesmo tempo se moldam e se amalgamam ao corpo como sapatos, mesmo que desajustados: "O senhor Joseph Walser deve aprender a perceber sem precisar de explicações. Há um exército que se aproxima e você quer explicações sobre os seus sapatos?" 35

Todas as personagens habitam uma impulsão morfológica do espaço em direção ao tempo mínimo do agora e em torno da constituição de um sentido imunológico que está a serviço das forças de tensão da convivência que, por sua vez, "abrem esferas de vidas concretas e mantém em forma improvisações locais." Algo como "não te preocupes com a criatividade do próximo dia; é suficiente que cada dia tenha o seu próprio impulso." ${ }^{36}$ É a série que pode armar, de algum modo, esta outra imagem do espaço. Quando os livros se superpõem, se justapõem, se amalgamam uns nos outros a partir de seus personagens, formando um palimpsesto como imagem ponderada ou uma massa informe - "primeiro em forma de pasta aglutinante, depois em forma de pasta consolidante". ${ }^{37}$ Por isso também o desenho de relações impensáveis como método investigativo, por isso a tentativa de instabilidade da escrita como um estado de dança.

\footnotetext{
${ }^{35}$ Ibidem, p. 14.

${ }^{36}$ SLOTERDIJK, Peter. Esferas III, op. cit., p. 195.

${ }^{37}$ CORTÁZAR, Julio. Histórias de cronópios e de famas. Trad. Glória Rodriguez. Rio de Janeiro: Civilização Brasileira, 2004, p. 61.
} 